\title{
Identifikasi Pengenalan Karakter Plat Nomor Kendaraan Menggunakan Jaringan Syaraf Tiruan Berbasis Citra Digital
}

\author{
Sufiatul Maryana, Arie Qur'ania, and Agung Prajuhana Putra \\ Program Studi Ilmu Komputer Universitas Pakuan \\ E-mail: sufiatul.maryana@unpak.ac.id
}

\begin{abstract}
Meningkatnya volume kendaraan bermotor yang terjadi saat ini membuat kebutuhan akan adanya sistem yang dapat diterapkan pada banyak aplikasi pemantauan aktivitas lalu lintas dantaranya pembayaran jalan tol elektronik, pelanggaran lalu lintas, pencurian kendaraan dan lain sebagainya. Tujuan dari peneltian ini adalah mengidentifikasi pengenalan karakter plat nomor kendaraan menggunakan Jaringan Syaraf tiruan berbasis citra digital, pengenalan karakter dan keberhasilan proses klasifikasi ditentukan dari keberhasilan ekstraksi fitur tiap karakter sehingga dengan bentuk karakter yang beragam akan menambah tingkat kesulitan dalam proses pengenalan. Pengenalan pola pada plat nomor kendaraan menggunakan métode Jaringan Syaraf Tiruan yang terdiri dari beberapa tahapan, yaitu deteksi lokasi plat nomor, praproses citra plat nomor, memilih data uji dan data latih, indentifikasi menggunkan JST diantaranya Model klasifikasi JST, pengujian JST dan Akurasi JST. Data yang diambil sebanyak 160 yang terdiri atas 40 citra wilayah Bogor (F), 40 citra wilayah Jakarta (B), 40 citra wilayah Bandung $(D)$ dan 40 citra wilayah Purwakarta $(T)$. Data dari masing-masing jenis plat nomor dibagi menjadi dua bagian, 30 buah untuk data latih dan 10 buah untuk data uji. Dari uji coba berdasarkan 40 data latih yang dilakukan terdapat 31 data uji yang terdefinisi atau akurasi sebesar 77,5\%. Ekstraksi ciri yang digunakan dalam penelitian ini terdiri atas 6 parameter yaitu nilai entropi, variants, means, red, green dan blue, sedangkan proses identifikasi menggunakan Jaringan Syaraf tiruan. Hasil identifikasi akan menampilkan data uji dengan kode wilayahnya berdasarkan nilai yang terdekat dengan data latih, sehingga mendapatkan hasil $77,5 \%$.
\end{abstract}

Kata Kunci: Multimedia Plat Nomor, Deteksi, JST

\begin{abstract}
The increasing volume of motorized vehicles that is happening now makes the need for a system that can be applied to many traffic monitoring applications and the purpose of payment of electronic toll roads, traffic violations, vehicle theft and so forth. The purpose of this research is to identify the character recognition of vehicle number plates using digital image-based artificial neural networks, character recognition and the success of the classification process is determined from the success of feature extraction of each character so that with a variety of character shapes will increase the level of difficulty in the recognition process. Pattern recognition on vehicle license plates uses Artificial Neural Network methods consisting of several stages, namely detection of location plate numbers, image plate preprocessing, selecting test data and training data, identification using ANN including ANN classification models, ANN testing and ANN accuracy. The data taken were 160 consisting of 40 images of the Bogor area (F), 40 images of the Jakarta area (B), 40 images of the Bandung region (D) and 40 images of the Purwakarta region $(T)$. Data from each type of number plate is divided into two parts, 30 for training data and 10 for test data. From trials based on 40 training data conducted there were 31 defined test data or an accuracy of $77.5 \%$. Feature extraction used in this study consists of 6 parameters, namely the entropy value, variants, means, red, green and blue, while the identification process uses artificial neural networks. The identification results will display the test data with the area code based on the value closest to the training data, so that the results are $77.5 \%$
\end{abstract}

Keywords: Multimedia Number Plate, Detection, JST. 


\section{Pendahuluan}

Salah satu bagian unik dari sebuah kendaraan bermotor adalah plat nomor polisi. Di Indonesia telah di tetapkan dalam aturan bahwa tanda plat nomor kendaraan harus menuhi syarat dalam segi bentuk, ukuran, warna, dan letak pemasangannya Tanda Nomor Kendaraan Bermotor yang selanjutnya disingkat TNKB adalah tanda regident Ranmor yang berfungsi sebagai bukti legitimasi pengoperasian Ranmor berupa pelat atau berbahan lain dengan spesifikasi tertentu yang diterbitkan Polri dan berisikan kode wilayah, nomor registrasi, serta masa berlaku dan dipasang pada Ranmor [1]. Pengenalan pola plat nomor dapat diterapkan pada banyak aplikasi pemantauan aktivitas lalu lintas diantaranya pembayaran jalan tol elektronik atau non tunai yang sudah diberlakukan mulai tanggal 30 Oktober 2017 menurut permen PUPR No 16 Tahun 2017, pembayaran pada area parkir maupun mendeteksi jumlah kendaraan berdasarkan wilayah Dalam pengenalan karakter keberhasilan proses klasifikasi ditentukan dari keberhasilan ekstraksi fitur dari tiap karakter sehingga dengan bentuk karakter yang beragam akan menambah tingkat kesulitan dalam proses pengenalan.

Penelitian plat nomor kendaran pernah dilakukan oleh Muhammad Ridho Putra pada tahun 2016 dengan judul Deteksi dan Identifikasi Plat Nomor Kendaraan Mobil Menggunakan Jaringa Syaraf Tiruan Learning Vector Quantization (LVQ) Berbasis Video, kemudian dilakukan oleh David pada tahun 2013 dengan judul Pengenalan Pola Plat Nomor Kendaraan Menggunakan Jaringan Syaraf Tiruan Backpropagation dan penelitian serupapernah dilakukan pula oleh Nur Wakhidah pada tahun 2012 dengan judul Deteksi Plat Nomor Kendaraan Bermotor Berdasarkan Area pada Image Segmentation.

Pada penelitian ini citra digital akan diambil obyek awal untuk menentukan apakah plat kendaraan tersebut dari wilayah Bogor atau bukan. Sehingga kedepannya diharapkan dapat mengetahui jumlah kendaraan yang masuk ke wilayah tertentu dalam hal ini kota Bogor.

Tujuan dari penelitian ini adalah mendeteksi plat nomor kendaraan berdasarkan wilayah menggunakan jaringan syaraf tiruan berbasis pengolahan citra digital, dengan mengambil bagian karakter berupa huruf awal dari plat nomor mobil yang mempunyai beberapa tahap diantaranya : pengambilan data menggunakan kamera, identifikasi data awal sebagai praproses dari penelitian ini, memilih data latih dan data uji, memodelkan dengan JST kemudian melihat hasil akurasi dari percobaan.

\section{Metodologi Penelitian}

Metode yang digunakan pada penelitian ini adalah seperti terlihat pada Gambar 1

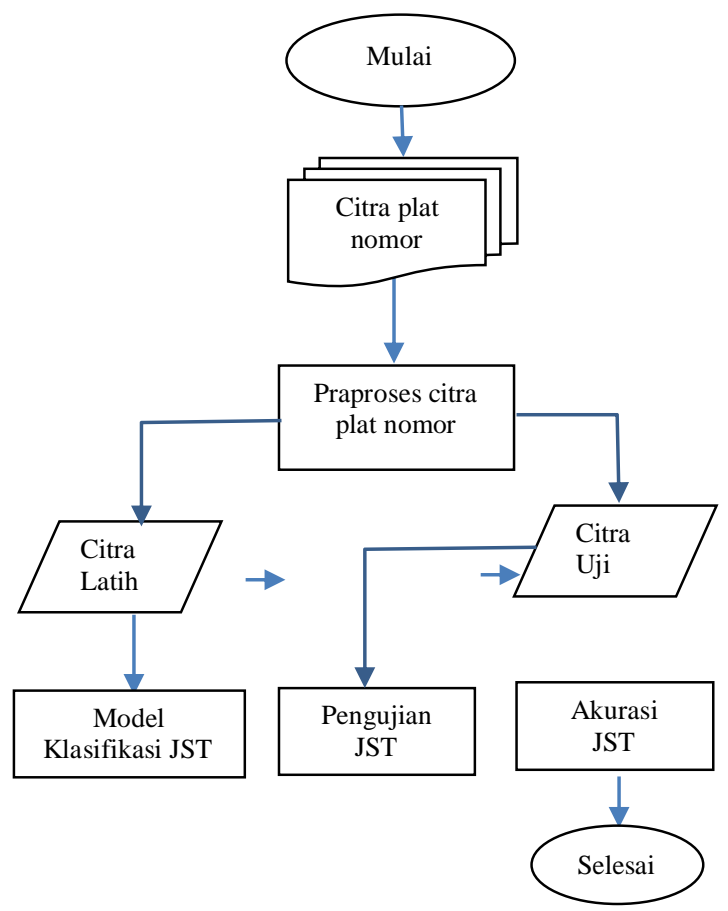

Gambar 1. Metode Penelitian

Komputasi Vol. 15, No. 1, January 2018: $89-139$ 


\subsection{Pengumpulan Data}

Tahap pengumpulan data dilakukan untuk mempermudah melakukan identifikasi data plat nomor kendaraan. Pengambilan data plat nomor kendaraan ini dilakukan dengan cara turun langsung ke lapangan diberbagai wilayah dan tempat, diantaranya Bogor, Jakarta, Bandung dan Purwakarta sebanyak 40 citra pada setiap wilayah. Data keseluruhan yang diambil pada penelitian ini adalah sebanyak 160 citra.

\subsection{Praproses Citra}

Praproses citra dilakukan dengan cara memotong citra nomor kendaraan dan memisahkannya dari latar citra kendaraan melalui proses segmentasi yang bertujuan untuk mendapatkan objek-objek yang terkandung didalam citra [6]. Citra yang telah disegmentasi kemudian diproses pengambilan ekstraksi ciri untuk 113ner mengenali ciri khas dari citra menggunakan analisis tekstur yaitu entropi, 113nergy, kontras, homogenitas. Ekstraksi ciri bertujuan untuk mengambil nilai dari sebuah citra untuk kemudian diproses melalui tahap identifikasi.

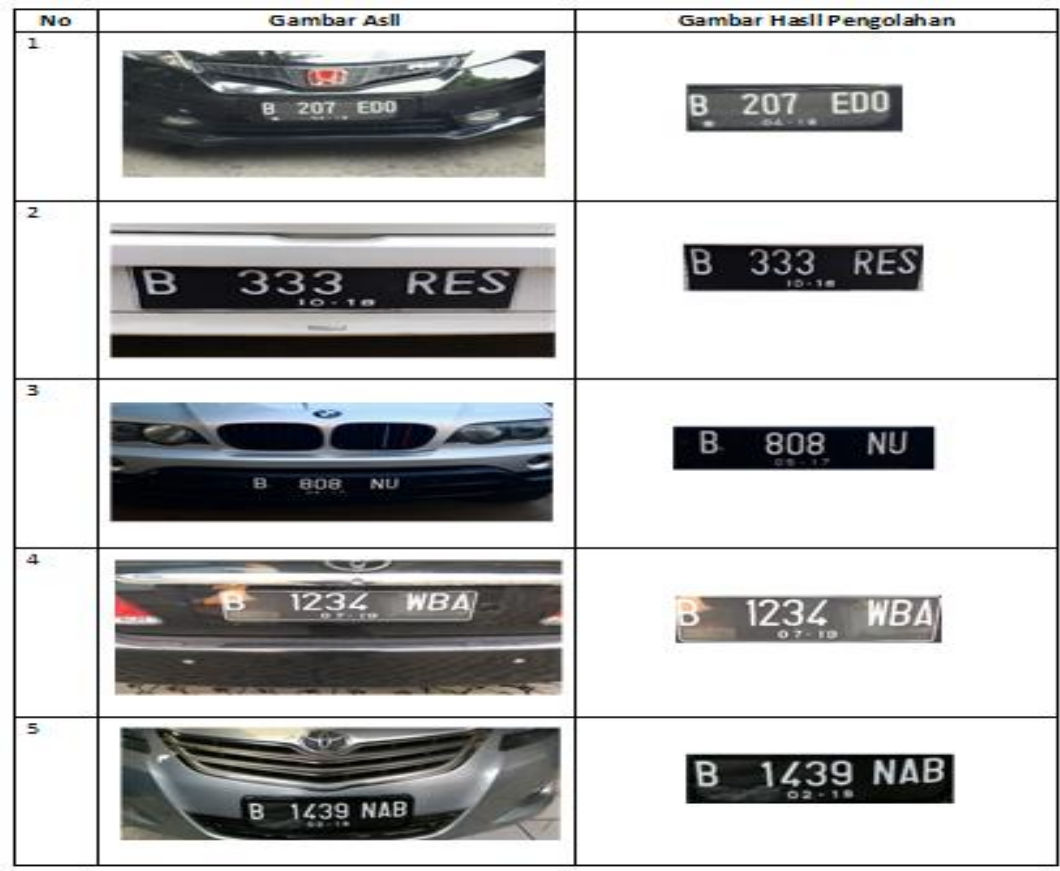

\subsection{Pembagian Data Uji dan Data Latih}

Gambar 2. Praproses Citra

Data plat nomor kendaraan pada penelitian ini sebanyak 160 citra yang terdiri atas 40 citra wilayah Bogor (F), 40 citra wilayah Jakarta (B), 40 citra wilayah Bandung (D) dan 40 citra wilayah Purwakarta $(T)$. Data dari masing-masing jenis plat nomor dibagi menjadi dua bagian, 30 buah untuk data latih dan 10 buah untuk data uji [1].

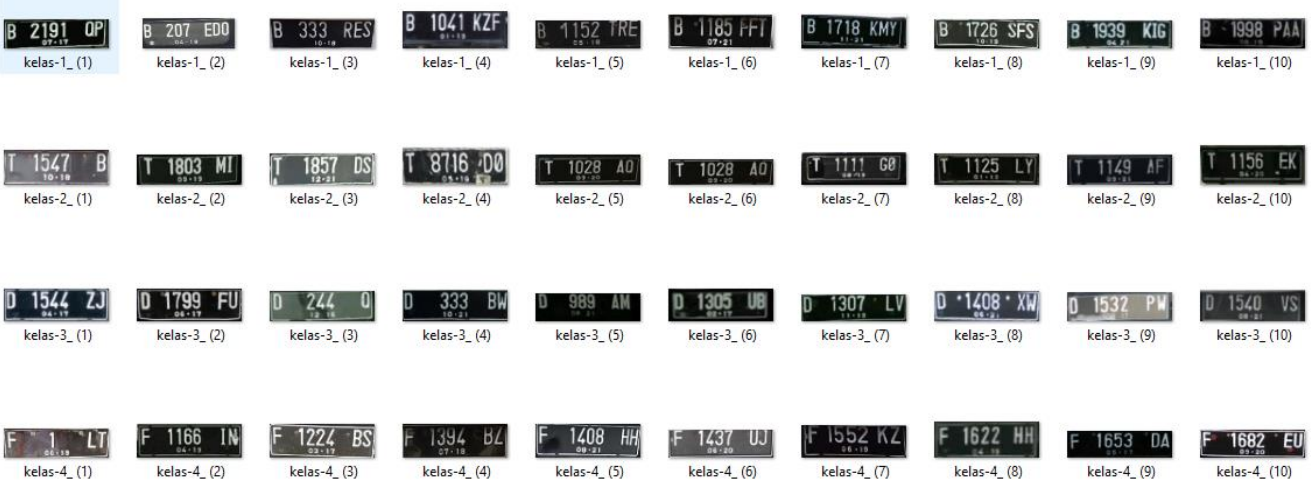

Gambar 3. Data Latih 


\subsection{Proses Identifikasi}

Citra hasil proses ekstraksi ciri menjadi inputan bagi Jaringan Syarat Tiruan. Banyaknya output adalah 4 kelas wilayah yaitu wilayah Bogor $(F)$, Jakarta $(B)$, Bandung (D), dan Purwakarta (T). Kelas 1 mencirikan wilayah Jakarta, kelas 2 mencirikan wilayah Purwakarta, kelas 3 mencirikan wilayah Bandung, dan kelas 4 mencirikan wilayah Bogor. Proses identifikasi menggunakan RGB pada citra ini lebih dominan warna hitam dimana warna hitam diberikan tiga unsur warna ya itu Red, Green, Blue [6], seperti dapat dilihat pada Gambar 4

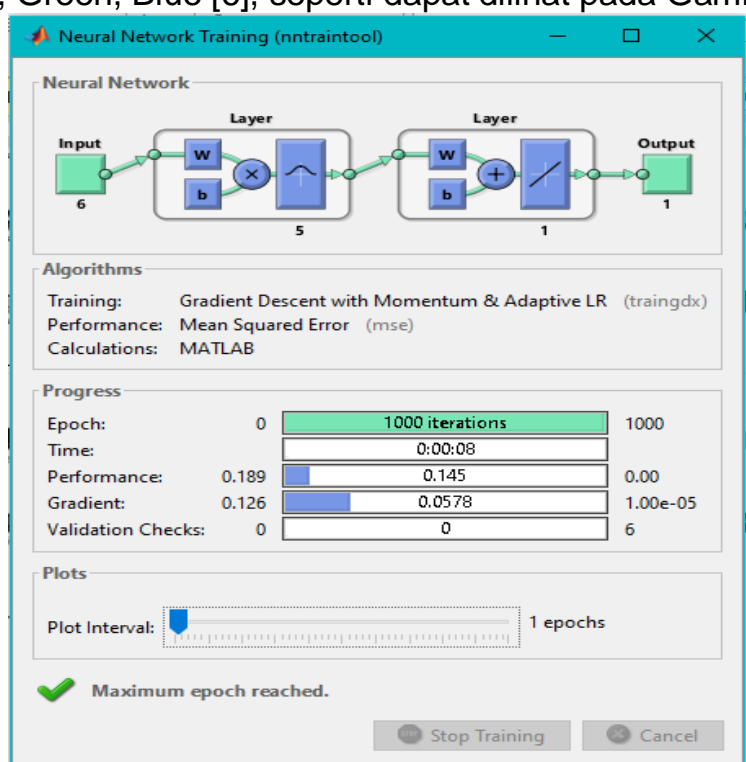

Gambar 4. Proses Identifikasi

\subsection{Akurasi}

Hasil penelitian diukur dengan akurasi untuk menilai kinerja menggunakan JST dalam identifikasi plat nomor yang dihitung berdasarkan data uji dengan rumus :

Akurasi $=\frac{\text { Jumlah Klasifikasi yang benar }}{\text { Jumlah semua data uji }} \times 100 \%$

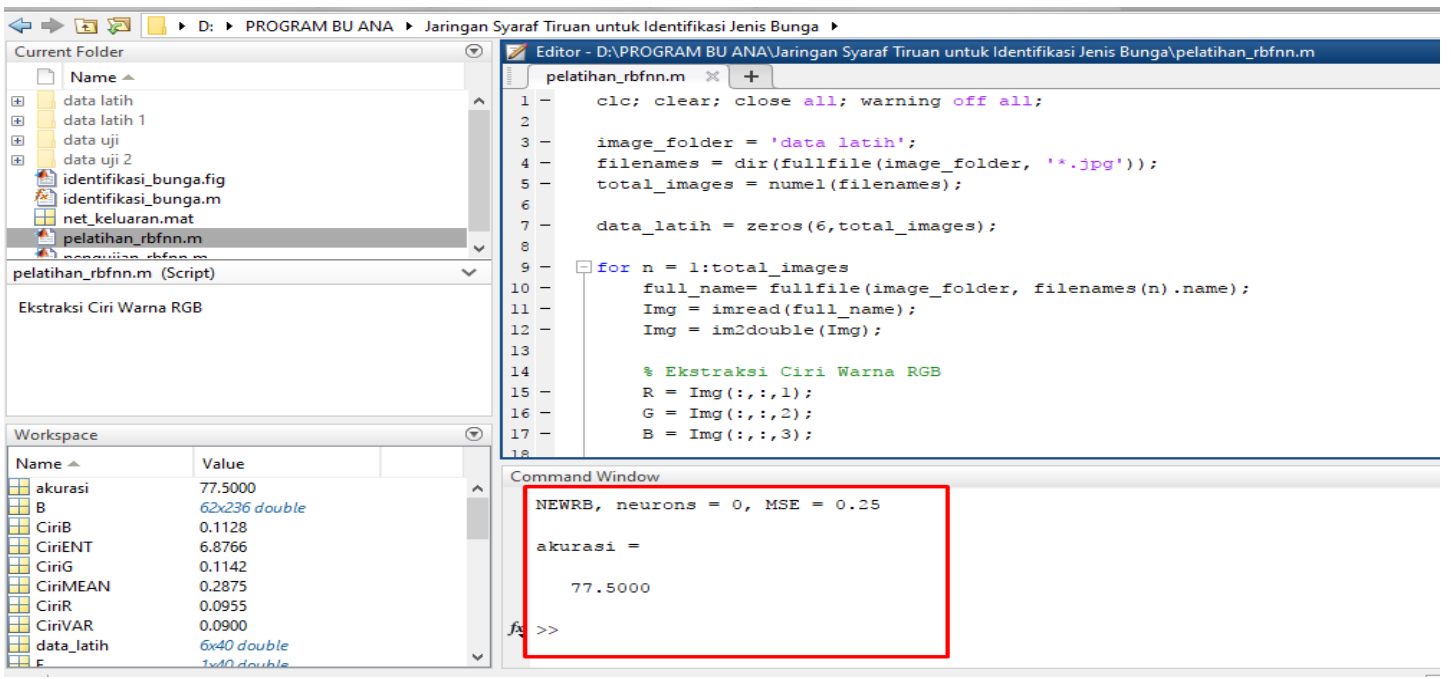

Gambar 5. Pengujian dengan data latih 
Gambar 5 menunjukan hasil pengujian dengan menggunakan data latih dari 4 kelas didapat akurasi sebesar $77,5 \%$.

\section{Hasil dan Pembahasan}

Data Plat Nomor dari Wilayah Bogor, Jakarta, Bandung dan Purwakarta sebanyak 30 citra pada setiap wilayah. Data keseluruhan yang diambil pada penelitian ini adalah sebanyak 160 citra. Proses Segmentasi citra. Citra yang telah disegmentasi kemudian diproses pengambilan ekstraksi ciri untuk bisa mengenali ciri khas dari citra menggunakan analisis tekstur yaitu entropi, energi, kontras, homogenitas.

Aplikasi identifikasi plat nomor berdasarkan wilayah berbasis gambar menggunakan Jaringan Syaraf Tiruan (JST)disusun seperti diagram alur yang disajikan pada Gambar 6 .

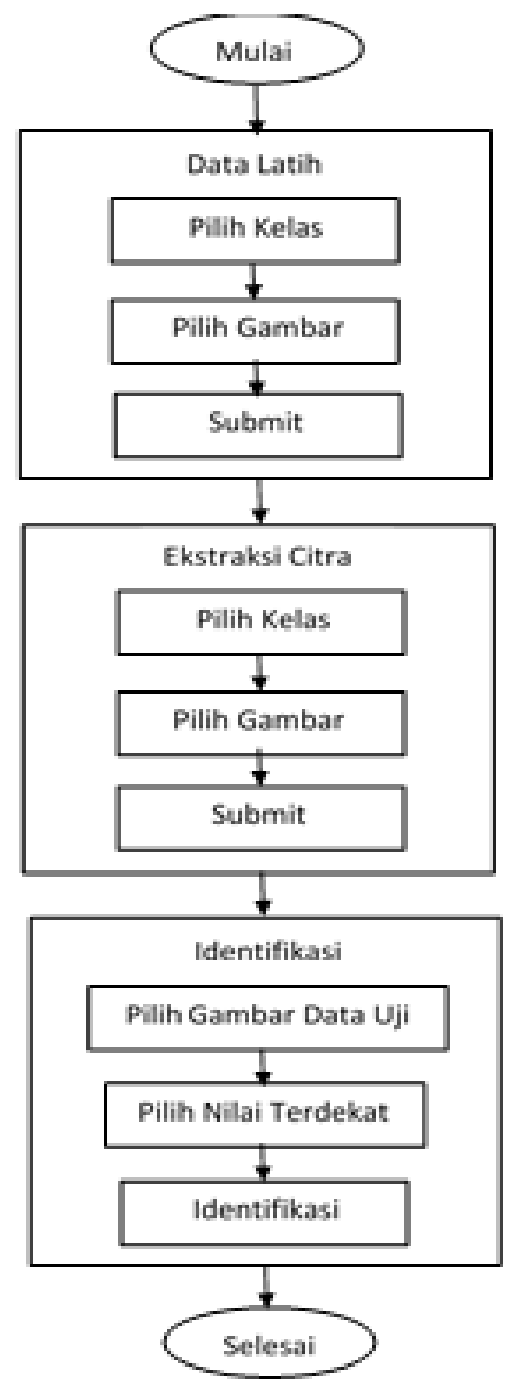

Gambar 6. Diagram alur Aplikasi

Hasil proses ekstraksi ciri dari 4 kelas plat nomor kendaraan berdasarkan wilayah yaitu Bogor (F), Jakarta (B), Bandung (D), dan Purwakarta (T) adalah dapat mengidentifikasi satu huruf awal dari setiap plat nomor yang diujikan, sehingga dapat terlihat banyaknya jumlah masing-masing wilayah sesuai dengan data yang diuji dengan capaian tingkat akurasi sebanyak $77,5 \%$. Berikut tampilan hasil data citra yang dapat diidentifikasi dan data yang tidak dapat diidentifikasi seperti pada Gambar 7. 


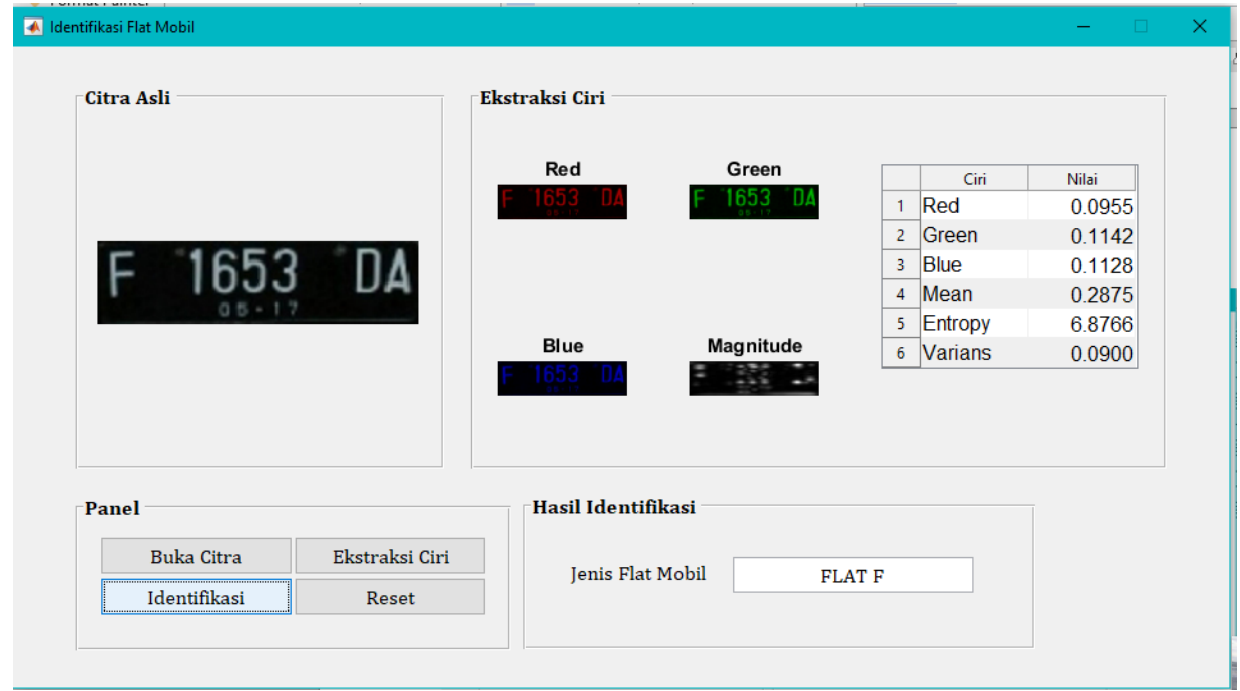

Gambar 7. Hasil Identifikasi yang sesuai

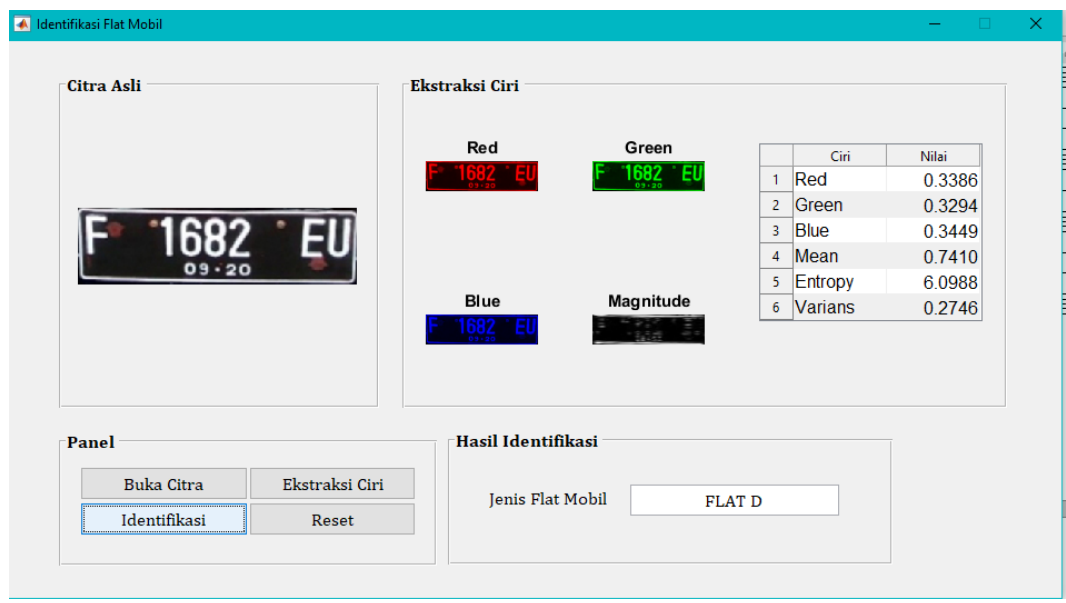

Gambar 8. Hasil Identifikasi yang tidak sesuai

Proses identifikasi dengan menginputkan data uji dengan cara memilih gambar yang akan diujikan ke dalam sistem. Hasil identifikasi akan menampilkan kode plat nomor berdasarkan wilayah. Aplikasi menampilkan nilai ekstraksi ciri dari citra data uji yaitu nilai entropi, variants, means, red, green dan blue.

\section{Kesimpulan}

Aplikasi Identifikasi plat nomor kendaraan berdasarkan wilayah menggunakan Jaringan Syaraf Tiruan (JST) berbasis pengolahan citra digital bertujuan untuk mengidentifikasi plat nomor menggunakan citra yang terbagi ke dalam 4 kelas yaitu kelas 1 untuk wilayah Jakarta (B), kelas 2 untuk wilayah Purwakarta (T), kelas 3 untuk wilayah Bandung (D), dan kelas 4 untuk wilayah Bogor $(F)$. Data yang diambil terdiri atas 160 buah, dengan masing-masing kelas terbagi atas 30 buah citra. Data citra dibagi ke dalam data latih sebanyak 120 buah dan 40 buah sebagai data uji. Ekstraksi ciri yang digunakan dalam penelitian ini terdiri atas 6 parameter yaitu nilai entropi, variants, means, red, green dan blue, sedangkan proses identifikasi menggunakan Jaringan Syaraf tiruan. Hasil identifikasi akan menampilkan data uji dengan kode wilayahnya berdasarkan nilai yang terdekat dengan data latih. Hasil uji coba menghasilkan nilai 77,5 persen. 


\section{References}

[1] Arymurthy. Pengantar Pengolahan Citra. Elex Media Komputindo. Jakarta. 2012.

[2] Hermawan, Arief. Teori dan Aplikasi Jaringan Syaraf Tiruan. Yogyakarta. 2006.

[3] Puspitaningrum, Diyah. Penghantar Jaringan Syaraf Tiruan. Yogyakarta. 2006.

[4] Putra R dkk. Deteksi Dan Identifikasi Plat Nomor Kendaraan Mobil Menggunakan Jaringan Syaraf Tiruan Learning Vector Quantization (Lvq) Berbasis Video. E-proceeding of engineering : Vol.3 No.1 April 2016

[5] Salsabilla, Munanto, Permata. Pengolahan Citra Digital. Seminar Nasional Teknologi Informasi dan Komunikasi. 2013

[6] Susanto, Adhi \& Kadir Abdul. Teori dan Aplikasi Pengolahan Citra. Andi Yogyakarta. 2013.

[7] Suprida, Cut Suprida. Implementasi Aqnalisis Tekstur Terhadap Daging Sapi dan Daging Babi. Skripsi. Jurusan Ilmu Komputer, FMIPA Universitas Pakuan. Bogor. 2015. 